\title{
Study on the Lactation Volume and Related Factors of Mother's Milk in Puerperal Women Separated from Infant
}

\author{
Dan Liu, Zhifang Zhang*, Liyuan Tian, Ling Zeng, Yanhui Deng \\ District III of Obstetrics, Foshan Women and Children's Hospital, Foshan, China \\ Email: *1973007364@qq.com
}

How to cite this paper: Liu, D., Zhang, Z.F., Tian, L.Y., Zeng, L. and Deng, Y.H. (2020) Study on the Lactation Volume and Related Factors of Mother's Milk in Puerperal Women Separated from Infant. Journal of Biosciences and Medicines, 8, 187195 .

https://doi.org/10.4236/jbm.2020.811017

Received: October 15, 2020

Accepted: November 21, 2020

Published: November 24, 2020

Copyright $\odot 2020$ by author(s) and Scientific Research Publishing Inc. This work is licensed under the Creative Commons Attribution International License (CC BY 4.0).

http://creativecommons.org/licenses/by/4.0/

\begin{abstract}
Objective: To investigate the lactation volume and milk secretion of mother's milk in puerperal women separated from mother and infant, and to study the related influencing factors. Methods: Selected February 2015-February 2020 in Foshan women and children's hospital 420 cases of maternal as the research object, using lactation related factors comprehensive questionnaire of maternal and infant separation of puerperal women for continuous determination of amount of lactation, and $1-7$ days and 8 to 14 days postpartum lactation quantity and Pearson correlation analysis, using multiple linear regression analysis to affect maternal separation of puerperal women in lactation of breast volume related factors were analyzed. Results: The lactation volume of the puerperal women was on the rise within 14 days after delivery. 14 days mammary volume ware $545.13-243.18 \mathrm{ml}$, postpartum lactation II period start time was $(67.48+26.57) \mathrm{h}$. The correlation coefficient between lactation volume on day 4 and lactation volume on day 14 was $0.04(\mathrm{P}<0.05)$. Pregnancy-induced hypertension syndrome, lactation II period start time, birth gestational age, maternal age is affecting maternal separation of the main factors of puerperal women lactation milk. Conclusion: Early maternal separation of puerperal women breast milk lactation quantity is little, lactation II later period start time, delay rate is high: in clinical nursing work, should pay attention to produce age is bigger, smaller gestational age and birth with pregnancy-induced hypertension syndrome, maternal lactation stage II startup delay, should be timely intervention of maternal and infant separation maternal management effectively, promote successful lactation and increase the amount of lactation, for clinical guidance and provides some references for the separation of puerperal women breastfeeding.
\end{abstract}

\section{Keywords}

Maternal and Child Separation, Obstetric Care, Puerperium, Lactation, 


\section{Introduction}

Mother-infant separation refers to the state of a newborn or infant being deprived of the care of the mother for a long time [1] [2]. Not only will it induce stress in the offspring and adversely affect behavior and nervous system development [3] [4], it will also affect the confidence of mothers in breastfeeding and increase the difficulty of breastfeeding [5]. Studies have found that breastfeeding can significantly reduce the incidence of nutritional and immune diseases such as necrotizing enterocolitis, sepsis, and meningitis, and reduce neonatal mortality [6] [7] [8]. At present, a series of studies on postpartum lactation and related factors have been carried out abroad. It is found that the time of milking and the frequency of milking are important factors that affect the amount of milk. At least 8 times a day of milking frequency is the prerequisite for maintaining sufficient lactation [9] [10]. In addition, insufficient social support affects maternal lactation and is a risk factor leading to reduction in maternal lactation. Data show that the global rate of exclusive breastfeeding within 6 months is less than $37 \%$, and maternal or neonatal diseases during delivery are the cause of early breastfeeding failure. The important reason for neonatal diseases during delivery is the cause of early breastfeeding failure [11] [12]. In clinical work, we have also found that the number of breastfeeding mothers and their compliance with mother-infant separation are low, which increases the possibility of lactation failure and makes it difficult to establish breastfeeding behavior. Therefore, this study explores the lactation volume and the law of milk secretion of puerperium women separated from mother and child, and studies related factors to promote the successful lactation of puerperium women separated from mother and infant, and increase the lactation rate, which is a clinical guide for the puerperium of mother-infant separation Women breastfeeding provide a reference basis.

\section{Methods}

\subsection{Research Object}

Selected 420 parturients who were separated from their mother and child in the obstetrics department of Foshan Maternal and Child Health Hospital from February 2015 to February 2020 as the research subjects. Inclusion criteria: mother-child separation time $\geq 3$ days; possible and voluntary exclusive breastfeeding without relevant contraindications; able to communicate in Mandarin or Cantonese, have a clear consciousness, can understand and complete the questionnaire, all subjects have informed consent and volunteer to participate in this study. Exclusion criteria: Children who died or gave up treatment within 3 days of hospitalization; had a history of mental and endocrine diseases before pregnancy. This study was approved by the Medical Ethics Committee of Foshan Maternal and Child Health Hospital. 


\subsection{Research Methods}

In this study, the questionnaire method was used to record the lactation volume and regularity of the selected mothers daily, including the date of milking, the start time of milking, the duration of milking, the volume of milk each time, the frequency of milk pumping per day, Sleep time, the start of lactation phase II, etc. Inform the parturient to start manual milking as soon as possible if the condition permits, 1 time/ 3 hours, no less than 30 minutes each time, day and night. When the parturient enters the second stage of lactation (referring to the parturient who feels that the breasts are suddenly full and start to produce a lot of milk, she will switch to a manual breast pump to pump: the duration of the breastfeeding is such that the milk will no longer be sprayed and become a droplet, then continue to pump 2 Minutes to ensure that the breast milk can be fully pumped out. Collection and measurement of breast milk: The first method of milking is collected in a sterile breast milk storage cup, and a disposable $5 \mathrm{ml}$ syringe is used to measure the amount of breast milk; when breast pumping, use a graduated pump The milk collection bottle collects and measures, and provides the breast milk after measurement to the newborn for consumption.

\subsection{Survey Tools}

The comprehensive questionnaire on factors related to lactation of puerperium women separated from mother and child includes maternal age, parity, pregnancy-induced hypertension syndrome, mode of delivery, breastfeeding experience, gestational age of newborns, birth weight of newborns, etc. Designed by the research team according to domestic and foreign literature and the characteristics of clinical work in our hospital [13]-[18].

\subsection{Data Collection Method}

The research data was collected by 6 nurses randomly selected from the obstetric ward of our hospital, and the research team provided special training and guidance to the 6 nurses. Train them to explain in detail the research purpose, research significance and cooperation methods to them when they are in the maternity hospital, and issue questionnaires to all research subjects who meet the selection criteria on the day of delivery after informed consent. It is collected on the spot after being filled out by the research subject. After discharge from the hospital, mothers were urged to express breast milk regularly and regularly by telephone every day, and related content such as lactation was collected and checked daily.

\subsection{Statistical Methods}

Use SPSS26.0 statistical software for statistical analysis of the data. Counting data is described by frequency and percentage; measurement data is described by mean \pm standard deviation for normal distribution, and median and interquartile range for non-normal distribution. The correlation between daily lactation 
was analyzed by Pearson correlation analysis, and multiple linear regression analysis was used for statistical analysis of influencing factors. P $<0.05$ was considered statistically significant.

\section{Results}

\subsection{General Situation of Research Objects}

In this study, a total of 420 comprehensive questionnaires on lactation-related factors of puerperium women who met the research standards were distributed. A total of 375 comprehensive questionnaires on lactation-related factors were returned, with a recovery rate of $89.29 \%$. The effective rate of the questionnaire was $98.13 \%$. Among them, 12 parturients withdrew due to personal reasons, and 32 parturients failed to record their lactation in time. We conducted a statistical analysis of 375 parturients with complete research data and found that they were $21-43(25.26 \pm 5.72)$ years old, of which 195 were primiparas (52\%), and 180 were postpartums (48\%); combined with pregnancy-induced hypertension 150 cases (40\%) had breastfeeding experience; 168 cases (44.8\%) had breastfeeding experience; delivery conditions: natural delivery 210 cases (56\%), cesarean section 165 cases (44\%); the average postpartum feeding time was $(8.27 \pm 5.52) \mathrm{h}$; the average daily breast pumping frequency was $(7.58 \pm 0.74)$ times; the average daily sleep time was $(8.72 \pm 1.69) \mathrm{h}$.

\subsection{The Lactation Volume and Its Regularity in the $14 \mathrm{~d}$ Postpartum}

Analyzing the collected data of 375 comprehensive questionnaires on lactationrelated factors, it was found that the daily lactation of puerperium women separated from mother and infant continued to increase within 14 days after delivery, and the largest increase in lactation on the $4^{\text {th }}$ day after delivery, an increase of $101.88 \mathrm{ml}$ from the previous day. $62.55 \mathrm{ml}$, the lactation volume after the $10^{\text {th }}$ day postpartum tends to be stable, the lactation volume on the $14^{\text {th }}$ day postpartum is $545.13 \mathrm{ml} \pm 243.18 \mathrm{ml}$; the start time of lactation phase II is $(67.48 \pm$ 26.57) $h$. The daily lactation output of puerperium women separated from mother and baby is shown in Table 1 .

\subsection{Analysis of Factors Related to Daily Lactation during the 14 Days Postpartum}

Using Pearson's correlation to analyze the correlation between lactation on days 1 - 7 and days 8 - 14 after delivery, it was found that the lactation on the $14^{\text {th }}$ day after delivery was correlated with the lactation in the first week after delivery, and the correlation coefficient showed a steady increase trend. The correlation coefficient between lactation on day 4 and lactation on day 14 increased the most, suggesting that lactation on day 4 can be used to predict stable lactation on day 14 , as shown in Table 2. 


\subsection{Multiple Linear Regression Analysis of Related Factors of Lactation on the $14^{\text {th }}$ Day Postpartum}

Multivariate linear regression analysis was used to statistically analyze the related factors of lactation on the $14^{\text {th }}$ day postpartum. The original values were entered into the maternal age (years), pregnancy-induced hypertension, the start time of lactation phase II, the postpartum milking time (h), and average smoking Milk frequency (times), average sleep time(h), gestational age of newborns (weeks), birth weight ( $\mathrm{g}$ ) of newborns. After multiple stepwise regression analysis, it was found that maternal age, pregnancy-induced hypertension, gestational age at birth, and the start time of lactation phase II were important factors affecting

Table 1. The amount of lactation in puerperium women separated from mother and baby in the 14 days after delivery $(\mathrm{n}=375, \mathrm{~m} 1)$.

\begin{tabular}{ccccc}
\hline $\begin{array}{c}\text { Postpartum time } \\
(\mathrm{d})\end{array}$ & $\begin{array}{c}\text { Mean } \pm \text { standard } \\
\text { deviation }\end{array}$ & Median & $\begin{array}{c}\text { Minimum } \\
\text { value }\end{array}$ & $\begin{array}{c}\text { Maximum } \\
\text { value }\end{array}$ \\
\hline 1 & $0.78 \pm 1.16$ & 0.60 & 0 & 11.80 \\
2 & $27.41 \pm 12.14$ & 3.10 & 0 & 98.00 \\
3 & $54.94 \pm 68.87$ & 23.72 & 0 & 467.00 \\
4 & $156.82 \pm 131.42$ & 137.00 & 1.40 & 651.00 \\
5 & $253.14 \pm 198.27$ & 184.50 & 11.00 & 976.00 \\
6 & $300.72 \pm 208.51$ & 235.00 & 37.00 & 945.00 \\
7 & $368.72 \pm 220.71$ & 296.00 & 53.00 & 1160.00 \\
8 & $402.82 \pm 226.42$ & 358.00 & 61.50 & 1210.00 \\
9 & $441.42 \pm 271.68$ & 378.50 & 32.00 & 1310.00 \\
10 & $75.82 \pm 213.40$ & 411.00 & 88.00 & 295.00 \\
11 & $511.20 \pm 217.57$ & 458.50 & 97.00 & 1264.00 \\
12 & $561.12 \pm 270.47$ & 462.00 & 104.00 & 3000.00 \\
13 & $543.4 \pm 251.47$ & 456.00 & 135.00 & 1438 \\
14 & $545.13 \pm 243.18$ & 452.50 & 111.00 & 298.00 \\
\hline
\end{tabular}

Table 2. Pearson correlation matrix (r value) of milk production within 14 days after delivery.

\begin{tabular}{cccccccc}
\hline $\begin{array}{c}\text { Postpartum } \\
\text { time (d) }\end{array}$ & $\mathbf{8}$ & $\mathbf{9}$ & $\mathbf{1 0}$ & $\mathbf{1 1}$ & $\mathbf{1 2}$ & $\mathbf{1 3}$ & $\mathbf{1 4}$ \\
\hline 1 & 0.326 & 0.324 & 0.318 & 0.298 & 0.283 & 0.319 & 0.304 \\
2 & 0.302 & 0.311 & 0.310 & 0.343 & 0.346 & 0.357 & 0.347 \\
3 & 0.564 & 0.528 & 0.517 & 0.564 & 0.568 & 0.571 & 0.568 \\
4 & 0.761 & 0.721 & 0.719 & 0.697 & 0.681 & 0.685 & 0.691 \\
5 & 0.860 & 0.848 & 0.841 & 0.794 & 0.783 & 0.791 & 0.726 \\
6 & 0.926 & 0.897 & 0.884 & 0.795 & 0.781 & 0.806 & 0.786 \\
7 & 0.971 & 0.953 & 0.948 & 0.897 & 0.884 & 0.847 & 0.842 \\
\hline
\end{tabular}


Table 3. Multiple linear regression analysis of factors related to lactation on the 14th day postpartum.

\begin{tabular}{cccccc}
\hline Variable & $\begin{array}{c}\text { Regression } \\
\text { coefficient }\end{array}$ & $\begin{array}{c}\text { Standard } \\
\text { error }\end{array}$ & $\begin{array}{c}\text { standardized } \\
\text { regression } \\
\text { coefficient }\end{array}$ & F value & P value \\
\hline $\begin{array}{c}\text { Constant term } \\
\text { Maternal age (years) }\end{array}$ & 461.12 & 478.74 & - & 0.86 & 0.35 \\
$\begin{array}{c}\text { Pregnancy induced hypertension } \\
\text { syndrome }\end{array}$ & -9.76 & 4.19 & -0.27 & 6.79 & 0.01 \\
$\begin{array}{c}\text { Newborn gestational age (weeks) } \\
\text { Start time of lactation stage II }\end{array}$ & -197.87 & 48.37 & -0.34 & 17.51 & $<0.05$ \\
\hline
\end{tabular}

postpartum lactation $(\mathrm{P}<0.05)$. See Table 3.

\section{Discussion}

Mother-infant separation refers to the state of a newborn or infant being deprived of the care of the mother for a long time. At present, studies have found that approximately 15 million premature babies are born every year worldwide, of which more than 1 million premature babies die because of complications such as sepsis, necrotizing enterocolitis, meningitis, etc. However, most of these complications are directly related to improper feeding. Breastfeeding can significantly reduce the incidence of sepsis, necrotizing enterocolitis, meningitis and other complications, and greatly reduce the mortality rate of newborns [19] [20]. In addition, postpartum mother-infant separation will not only induce stress in the newborn and adversely affect behavior and neurological development, but also affect the confidence of mothers in breastfeeding and increase the difficulty of breastfeeding. In clinical work, we have also found that the number of breastfeeding mothers and their compliance with separated mothers and babies are low, which increases the possibility of lactation failure and makes it difficult to establish breastfeeding behavior. Therefore, it is of great clinical significance to study the lactation volume and the law of milk secretion of puerperium women separated from mother and child, and to study the relevant influencing factors.

In this study, we used Pearson's correlation to analyze the correlation between lactation on days 1 - 7 and days 8 - 14 after delivery, and found that there was a correlation between lactation on the $14^{\text {th }}$ day and the first week after delivery, and the correlation coefficient was stable. Increasing trend, the correlation coefficient between lactation on day 4 and lactation on day 14 increased the most. It can be seen that it is very important to observe the milk production on the $4^{\text {th }}$ day of postpartum, which can be used as a predictor of whether postpartum milk production is sufficient, which is similar to the results of similar studies reported abroad [21] [22] [23]. Clinical nursing staff should dynamically monitor the milk production on the $4^{\text {th }}$ day after delivery, guide the mothers to correct milking techniques, enhance their confidence in breastfeeding, and help them increase 
milk production. In addition, we found through multiple stepwise regression analysis that maternal age, pregnancy-induced hypertension, neonatal gestational age, and the start time of phase II lactation are important factors affecting postpartum lactation $(\mathrm{P}<0.05)$, and the start time of phase II lactation is An important factor that affects maternal lactation. Poor lactation in the early postpartum period will continue to affect the production of late milk secretion, which has been consistent with foreign studies [24] [25].

In clinical work, our nursing staff should actively carry out health education for the mothers, explain the advantages of breastfeeding to the mothers and their families, the importance of early sucking, frequent sucking, and on-demand breastfeeding, and explain the occurrence of nipple pain and breasts to the mothers and their families. The cause of the pain is to instruct the mother to take a rest, keep a happy mood, and guide her family members to ensure a balanced diet, eat soups with high protein, high calories, and high vitamins, and maintain adequate milk. Early detection of pregnancy-induced hypertension and early treatment; after childbirth, instruct mothers to prescribe milk as soon as possible within 1 hour after delivery, promote the start time of lactation phase II, and increase lactation, and provide a reference for clinically guiding breastfeeding of puerperium women who are separated from mother and baby.

\section{Conflicts of Interest}

The authors declare no conflicts of interest regarding the publication of this paper.

\section{References}

[1] Blencowe, H., Cousens, S., Oestergaard, M.Z., et al. (2012) National, Regional, and Worldwide Estimates of Preterm Birth Rates in the Year 2010 with Time Trends since 1990 for Selected Countries: A Systematic Analysis and Implications. The Lancet, 379, 2162-2172. https://doi.org/10.1016/S0140-6736(12)60820-4

[2] Mansoori, H., Barzoki, A.S., Javadi, M.H.M., et al. (2019) Exploring the Role of Human Resource Practices in Organisational Empowerment in Developing Countries: Evidence from the Power Industry in Iran. International Journal of Business and Systems Research, 13, 21-46. https://doi.org/10.1504/IJBSR.2019.096363

[3] Huo, T.Z. and Mao, M. (2019) Common Problems and Solutions in Breastfeeding. Chinese Journal of Pediatrics, 57, 75-77.

[4] Máca, F., Kudrnovský, J., Baláž, P., et al. (2019) Tetragonal CuMnAs Alloy: Role of Defects. Journal of Magnetism and Magnetic Materials, 474, 467-471. https://doi.org/10.1016/j.jmmm.2018.10.145

[5] Wu, H.-P., Yin, T., Hsieh, K.-H., et al. (2020) Integration of Different Sensory Interventions from Mother's Breast Milk for Preterm Infant Pain during Peripheral Venipuncture Procedures: A Prospective Randomized Controlled Trial. Journal of Nursing Scholarship, 52, 10-18. https://doi.org/10.1111/jnu.12530

[6] Feng, Z. and Li, W. (2019) The Research Progress of Milk Production in Different Lactation Stages of Mothers of Premature Infants. Chinese Journal of Nursing, 54, 780-785.

[7] Takai, A., Hasegawa, T., Furukawa, T., Tajiri, T., et al. (2019) Ultrasonographic 
Findings of Multiple Intussusception in an Extremely Preterm Infant. Archives of Disease in Childhood Education \& Practice Edition, 104, 488-492. https://doi.org/10.1136/archdischild-2018-314885

[8] Renaud, M., Fath, L., Cheptou, M., et al. (2019) Iatrogenic Meningoencephalocele after Traumatic Perforation of the Cribriform Plate during Nasal Intubation of a Preterm Infant. International Journal of Pediatric Otorhinolaryngology, 118, 120-123. https://doi.org/10.1016/j.ijporl.2018.12.016

[9] Klingenberg, C., Muraas, F.K., Isaksen, C.E., et al. (2019) Growth and Neurodevelopment in Very Preterm Infants Receiving a High Enteral Volume-Feeding Regimen-A Population-Based Cohort Study. The Journal of Maternal-Fetal \& Neonatal Medicine, 32, 1664-1672. https://doi.org/10.1080/14767058.2017.1414796

[10] Gong, W.Y., Yue, X.F., Li, S.T., et al. (2019) The Effect of Intravenous Dezocine Analgesia on the Nutritional Composition of Breast Milk after Cesarean Section. Shanxi Medical Journal, No. 20, 2459-2462.

[11] Lloyd, M.L., Malacova, E., Hartmann, B., et al. (2019) A Clinical Audit of the Growth of Preterm Infants Fed Predominantly Pasteurised Donor Human Milk v. Those Fed Mother's Own Milk in the Neonatal Intensive Care Unit. British Journal of Nutrition, 121, 1-8. https://doi.org/10.1017/S0007114519000357

[12] Zheng, S.W. (2019) The Effect of Breast Massage on Improving Lactation and Breastfeeding Self-Confidence of Mothers Separated from Mother and Infant. Electronic Journal of Practical Clinical Nursing, No. 38, 231-236.

[13] Bhatia, J. (2013) Human Milk and the Premature Infant. Annals of Nutrition and Metabolism, 62, 8-14. https://doi.org/10.1159/000351537

[14] Fewtrell, M.S., Kennedy, K., Ahluwalia, J.S., et al. (2016) Predictors of Expressed Breast Milk Volume in Mothers Expressing Milk for Their Preterm Infant. Arch Dis ADC Fetal \& Neonatal Edition, 101, 308-321. https://doi.org/10.1136/archdischild-2015-308321

[15] Fabiyi, C., Rankin, K., Norr, K., et al. (2015) The Association of Low Social Support with Breast Milk Expression in Low-Income Mother Preterm Infant Dyads. Journal of Human Lactation, 31, 490-497. https://doi.org/10.1177/0890334415586199

[16] Healy, D.B., Brennan, A.M., O’Donovan, R., et al. (2016) Structured Promotion of Breastmilk Expression Is Associated with Shortened Hospitalisation for Very Preterm Infants. Acta Paediatrica, 105, 252-256. https://doi.org/10.1111/apa.13399

[17] Wang, C.Y., Quan, M.Y., Wang, W., et al. (2019) Investigation of Breastfeeding Status and Influencing Factors of Breast Milk Collection among Hospitalized Children in Neonatal Intensive Care Unit. Journal of Clinical Medicine, 47, 784-787.

[18] Matias, S.L., Dewey, K.G., Quesenberry, C.P. and Gunderson, E.P. (2014) Maternal Prepregnancy Obesity and Insulin Treatment during Pregnancy Are Independently Associated with Delayed Lactogenesis in Women with Recent Gestational Diabetes Mellitus. The American Journal of Clinical Nutrition, 99, 115-121. https://doi.org/10.3945/ajcn.113.073049

[19] Murase, M., Nommsen-Rivers, L., Morrow, A.L., et al. (2014) Predictors of Low Milk Volume among Mothers Who Delivered Preterm. Journal of Human Lactation, 30, 425-435. https://doi.org/10.1177/0890334414543951

[20] Hron, M., Goulet, C., Garofalo, C., et al. (2014) Acceptability and Feasibility of a Breast Milk Expression Education and Support Intervention in Mothers of Preterm Infants. Advances in Neonatal Care, 14, E9-E19. https://doi.org/10.1097/ANC.0000000000000113

[21] Zhang Guiqing, Liu Junli, Luo Yihua, et al. (2019) The Effect of Breast Massage after 
Cesarean Section on Lactation and Breast Pain. Journal of Bengbu Medical College, No. 6, 1-5.

[22] Omarsdottir, S., Adling, A., Bonamy, A.K., et al. (2015) Predictors of Sustained Maternal Milk Feeds in Extremely Preterm Infants. Journal of Perinatology, 35, 367-372. https://doi.org/10.1038/jp.2014.212

[23] Zhu Yimin, Liu Tan, Su Xiao, et al. (2019) Analysis of Related Factors of Insufficient Breast Milk Secretion in Puerperium Women. Chinese Journal of Reproductive Health, 30, 545-548.

[24] Dosani, A., Hemraj, J., Premji, S.S., et al. (2016) Breastfeeding the Late Preternl Infant: Elperiences of Mothers and Perceptions of Public Health Nurses. International Breastfeeding Journal, 12, Article No.: 23.

https://doi.org/10.1186/s13006-017-0114-0

[25] Van Vo, T., Hoa, T.K.D. and Hoang, T.D. (2017) Postpartum Depressive Symptoms and Associated Factors in Married Women: A Gross-Sectional Study in Danang City, Vietnam. Frontiers in Public Health, 5, 93-100.

https://doi.org/10.3389/fpubh.2017.00093 